\title{
Avaliação motora de crianças através do TGMD-3
}

\section{Motor assessment of children through TGMD-3}

\author{
Maria Eduarda de Oliveira Duarte ${ }^{1}$, Luana Andrade Rogeri², \\ Juliana Bayeux Dascal ${ }^{3}$
}

\begin{abstract}
Resumo
O presente trabalho trata-se de um estudo realizado com 17 crianças com faixa etária entre 4 e 5 anos, todas matriculadas no Centro de Educação Infantil - campus da Universidade Estadual de Londrina (CEI-UEL), tendo como objetivo avaliar o desempenho motor dessas crianças através do TGMD-3, antes e após uma intervenção motora, realizada no CEI-UEL. A intervenção foi composta de 29 sessões de 60 minutos em que eram trabalhadas diferentes habilidades motoras, após a qual foi aplicado novamente o TGMD-3 para avaliar se a intervenção havia influenciado positivamente o desempenho das crianças da amostra. Nossos resultados mostraram que para a variável somatória das habilidades de locomoção e habilidades com bola foi apresentado um aumento na comparação do pré-teste para o pós-teste, porém somente nas habilidades de locomoção foi encontrada significância na melhora. Quanto ao percentil, nas habilidades com bola foi encontrado um desempenho inferior no pós-teste, mas sem que houvesse diferença significativa entre os resultados; já para as habilidades de locomoção foi encontrada uma melhora no pós-teste do percentil, mas sem diferença significativa em comparação ao pré-teste. Com relação ao escore não foi encontrada diferença significativa para as habilidades, porém nas habilidades de locomoção houve desempenho superior no pós-teste e nas habilidades com bola houve desempenho inferior. Como conclusão, podemos inferir que a intervenção motora foi positiva para a melhora do desempenho das crianças, mas não para todas as variáveis analisadas, demonstrando que a intervenção motora pode ser uma ferramenta benéfica para o desempenho motor de crianças.
\end{abstract}

Palavras-chave: Infância; Intervenção motora; Habilidade motora.

${ }^{1}$ Graduanda em Educação Física (Bacharelado) na Universidade Estadual de Londrina (UEL), Londrina, Paraná, Brasil. E-mail: duda.oliduarte@uel.br

${ }^{2}$ Graduanda em Educação Física (Bacharelado) na Universidade Estadual de Londrina, Londrina, Paraná, Brasil.

${ }^{3}$ Doutorado em Ciências da Motricidade pela Universidade Estadual Paulista “Júlio de Mesquita Filho" (Unesp), Rio Claro, São Paulo, Brasil. Professora do Departamento de Educação Física da Universidade Estadual de Londrina, Londrina, Paraná, Brasil. 


\begin{abstract}
The present work is a study carried out with 17 children aged between 4 and 5 years old, all enrolled at the Child Education Center - campus of Universidade Estadual de Londrina (CEI-UEL), with objective of evaluating children motor performance through the TGMD-3, before and after a motor intervention, performed at CEI-UEL. The intervention consisted of 29 60-minute sessions with different motor skills, and after the 29 sessions, TGMD-3 was applied again to assess whether the intervention had positively influenced the performance of the children in the sample. Our results showed that for the sum of the walking and ball skills showed an increase in the comparison of the pre-test to the post-test, but only in the walking skills the difference was significant. As for the percentile, in the skills with the ball a lower performance was found in the post-test, but without any significant difference between the results; for the locomotion skills, an improvement was found in the post-test according to the percentile, not showing a significant difference compared to pretest. Regarding the score, no significant difference was found for the skills, but in the locomotion skills there was a superior performance in the post-test and in the skills with ball there was a lower performance. As a conclusion, we can deduce that motor intervention was positive for improving children motor performance, but not for all variables, showing that the motor intervention could be a beneficial tool to children motor performance.
\end{abstract}

Keywords: Childhood; Motor intervention; Motor skill.

\section{Introdução}

Para que a criança consiga desenvolver suas habilidades em um nível satisfatório quando relacionado à sua idade, se torna necessário a passagem pelos estágios do desenvolvimento motor. De acordo com Gorla, ${ }^{(1)}$ é importante a criança se inserir em um ambiente que a estimule e a prepare para a utilização de todas as suas capacidades e habilidades. Sendo assim, quanto mais diferenciadas forem as suas vivências, mais desenvolvido será o seu repertório motor e por consequência maior será a qualidade de seus movimentos.

Como se espera que a criança aprimore seu repertório motor ao longo do processo de desenvolvimento, uma das formas de verificarmos como esse processo ocorre é através da avaliação motora. A avaliação pode ser definida como coleta e interpretação de informações relevantes a respeito de um indivíduo a fim de que auxilie na tomada de decisões válidas, confiáveis e que não sejam discriminatórias. Para se avaliar o desenvolvimento motor de uma criança, a medida pode se estender do teste formal a uma observação informal da criança em seu ambiente natural. ${ }^{(1)}$

Essa avaliação se dá a partir da adequação das interpretações das medidas que foram coletadas anteriormente, ou seja, o quanto o seu desempenho é satisfatório de acordo com as normas de testes avaliativos ou de comportamentos esperados para aquele determinado indivíduo, classe ou unidade instrutiva. ${ }^{(2)}$

A avaliação motora serve a um objetivo muito importante na área do desenvolvimento motor, pois possibilita o entendimento de características motoras que possam identificar possíveis atrasos e levantem estratégias instrutivas para crianças ou outros grupos etários. ${ }^{(3)}$

O Test of Gross Motor Development (TGMD) é um instrumento destinado à avaliação de habilidades motoras fundamentais de crianças entre $3 \mathrm{e}$ 10 anos, foi desenvolvido por Dale Allen Ulrich em 1985 e aplicado a uma amostra de 909 crianças. Esta versão do teste foi utilizada durante 15 anos por pesquisadores e educadores, levantando e auxiliando o entendimento do desempenho de habilidades motoras fundamentais em diversos grupos etários. Em 2000, uma segunda versão foi publicada, intitulada TGMD-2, com algumas modificações metodológicas e aplicada a uma amostra de 1208 crianças de 10 estados norte-americanos. ${ }^{(4)}$

A partir de 2019, a nova versão do TGMD, intitulada TGMD-3 foi publicada por Ulrich, ${ }^{(5)}$ a partir da indicação de diversos pesquisadores 
e revisores que utilizaram o TGMD-2, e algumas modificações foram feitas. De maneira geral, as habilidades de controle de objetos passaram a ser denominadas de controle de bola, no subteste de locomoção, a habilidade skip (salto com sobrepasso) foi adicionada e o leap (salto com obstáculo) foi removido. No subteste de habilidade de controle de bola a rebatida de forehand com uma mão foi adicionada e a habilidade de rolar a bola foi modificada para a habilidade de lançar a bola por baixo.

O TGMD em suas várias versões, portanto, é um teste importante para auxiliar o entendimento do desempenho motor de crianças e identificar as que apresentam atraso motor, no planejamento de intervenções motoras, para avaliar o progresso do desempenho em diferentes habilidades motoras, e consequentemente o sucesso de intervenções motoras, além de servir como ferramenta em pesquisas científicas. ${ }^{(4-5)}$

\section{Justificativa}

A avaliação motora é uma ferramenta importante e que pode auxiliar profissionais de Educação Física a entenderem o desempenho motor e ajustarem suas intervenções a fim de alcançarem de maneira efetiva seus objetivos. O TGMD-3 poderá auxiliar o entendimento de características motoras de crianças, já que é um teste bastante utilizado no Brasil e em diversos países, pois permite o entendimento do desempenho motor, trazendo critérios de avaliação claros e precisos e tabelas comparativas para diferentes faixas etárias na infância (entre $3 \mathrm{e}$ 10 anos). ${ }^{(5)}$

Assim, compreender o desempenho motor de crianças de 4 a 5 anos, através do TGMD-3, que participam de uma intervenção motora, no município de Londrina, estado do Paraná, Brasil, pode complementar dados já obtidos em outros grupos e com outras intervenções no Brasil e mundialmente, e com isso aprofundar os conhecimentos relacionados ao comportamento motor, permitindo discussões e compreensão de intervenções mais efetivas para essa faixa etária.

\section{Objetivo}

Avaliar o desempenho motor de crianças de 4 a 5 anos de idade, através do TGMD-3, antes e após intervenção motora, realizada no Centro de Educação Infantil (CEI) da Universidade Estadual de Londrina (UEL), em Londrina, Paraná.

\section{Material e Método}

\section{Amostra}

Participaram deste estudo crianças que frequentavam o Centro de Educação Infantil da UEL (CEI-UEL) das turmas E4 e E5 com faixas etárias de 4 e 5 anos respectivamente. Inicialmente todas as crianças dessas turmas foram convidadas e/ou participaram dos testes (versão 3 do Test of Gross Motor Development - TGMD-3), mas ao longo do processo de coleta de dados, alguns participantes ou por não estarem presentes no dia da coleta, ou por não terem seus termos de consentimento livre e esclarecido (TCLEs) assinados por seus responsáveis, ou por dano de armazenamento ou captura de vídeo ou por não conseguirem completar todos os testes ou não se disponibilizarem a realizá-los, tiveram seus dados descartados.

Ao final do pré-teste e do pós-teste, 17 crianças participaram efetivamente do estudo, com média de idade de 3,90 anos e desvio-padrão de 0,75.

Todos os responsáveis pelas crianças que participaram deste estudo foram convidados a ler e assinar o TCLE. Este estudo foi aprovado pelo Comitê de Ética em Pesquisa Envolvendo Seres Humanos da Universidade Estadual de Londrina (CEP-UEL), sob parecer $n^{\circ} 3.382 .344$ e CAAE $n^{\circ}$ 12988419.1.0000.5231.

Como critério de inclusão, as crianças precisavam ter participado das intervenções com $75 \%$ de frequência (a participação média das crianças nas atividades foi de 87,5\%, semelhante a estudos prévios. ${ }^{(6-7)}$ ) Como critério de exclusão, as crianças que não conseguiram demonstrar compreensão e estar atentas ao que o teste exigia para ser desempenhado não participaram da amostra. 


\section{Teste}

Foi aplicado o TGMD-3, que inclui habilidades de locomoção e controle de bola. A parte de locomoção é composta por seis itens, sendo eles: correr, galopar, saltar com um pé, salto horizontal, skip e deslizar. Já a parte de controle de bola é composta por sete itens, sendo eles: rebater com as duas mãos, rebater com uma mão, quicar, pegar, chutar, arremesso por cima e lançamento por baixo.

Os subtestes funcionam conforme a seguir.

Correr: após a criança realizar uma breve corrida em linha reta, deve-se analisar se esta criança possui um breve momento em que ambos os pés estão fora do chão, se os braços estão em oposição às pernas com os cotovelos flexionados, se a criança apóia nos calcanhares ou dedos ao realizar o movimento e se a perna de não suporte realiza uma flexão por volta de $90^{\circ}$.

Figura 1 - Habilidade correr.

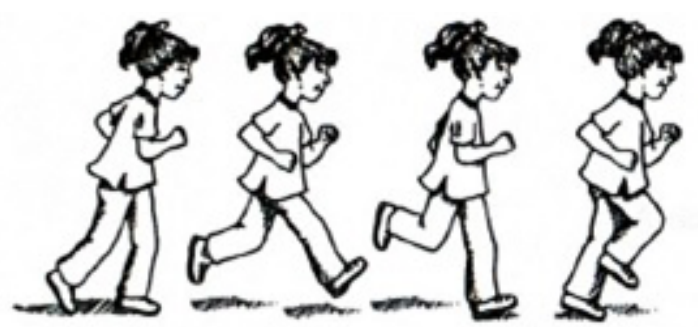

Fonte: Ulrich. ${ }^{(5)}$

Galopar: os braços devem ser flexionados e levados à altura da cintura durante a decolagem, realizar um passo à frente com a perna de liderança enquanto a de arrasto permanece atrás da que lidera, permanecer com os dois pés fora da superfície por um breve período e realizar quatro galopes consecutivos.

Figura 2 - Habilidade galopar.
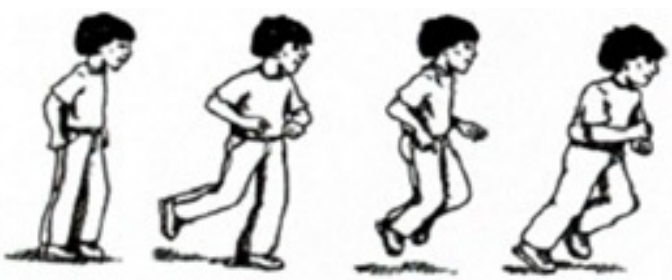

Fonte: Ulrich. ${ }^{(5)}$
Saltar com um pé: a perna que não está saltando é lançada para frente em um balanço pendular para produzir força, o pé que não está saltando permanece atrás da perna que salta, os braços são flexionados e balançam para frente produzindo força e a criança deve realizar quatro saltos consecutivos.

Figura 3 - Habilidade saltar com um pé.

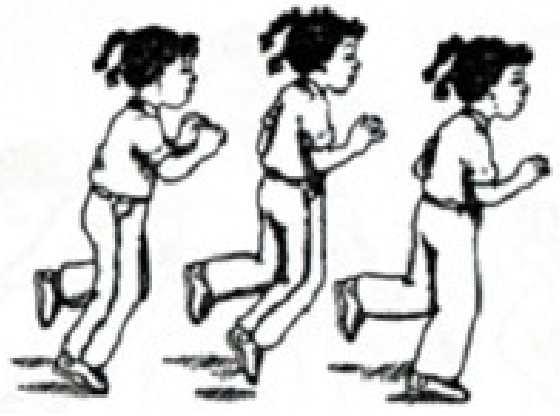

Fonte: Ulrich. ${ }^{(5)}$

Skip: deve-se realizar um passo para frente seguido de um salto com o mesmo pé, os braços são flexionados e se movem em oposição às pernas para produzir força, além de completar quatro saltos com sobrepassos contínuos e alternados ritmicamente.

Figura 4 - Habilidade skip.
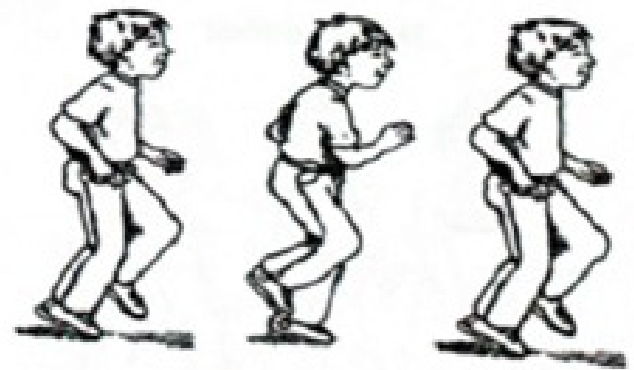

Fonte: Ulrich. ${ }^{(5)}$

Salto horizontal: antes da decolagem, ambos os joelhos são flexionados e os braços são estendidos atrás das costas; durante a decolagem os braços são estendidos forçadamente para frente e para cima alcançando acima da cabeça, ambos os pés devem sair e chegar ao chão juntos, e após a decolagem ambos os braços são forçados para baixo (durante a aterrissagem). 
Figura 5 - Habilidade salto horizontal.

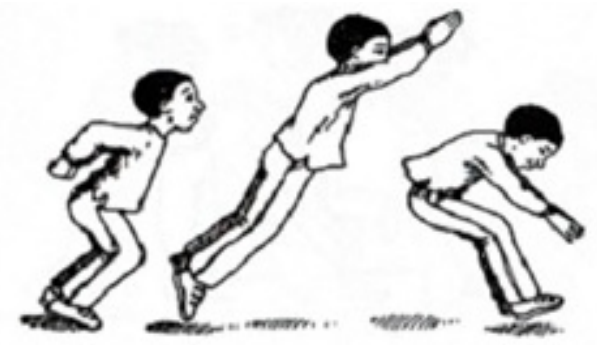

Fonte: Ulrich. ${ }^{(5)}$

Deslizar: o corpo deve estar virado para o lado a fim de que os ombros estejam alinhados com a linha do chão; é realizado um passo para o lado com um pé liderando seguido por um deslize com o pé de arrasto em que há um breve momento em que ambos os pés saem da superfície. Deve-se realizar quatro deslizes contínuos para o lado preferido e quatro deslizes contínuos para o lado não preferido.

Figura 6 - Habilidade deslizar.

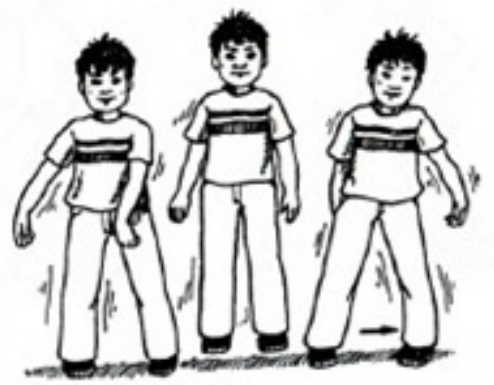

Fonte: Ulrich. ${ }^{(5)}$

Rebater com as duas mãos: a mão preferida da criança faz preensão no taco/bastão acima da mão não preferida, o quadril e ombros não preferidos devem estar voltados para frente e precisam realizar rotação e derrotação durante o balanço; são realizados passos em direção à bola com o pé não preferido e deve-se bater na bola a enviando para frente.

Figura 7 - Habilidade rebater com as duas mãos.
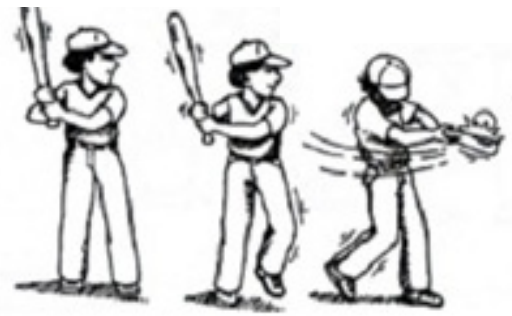

Fonte: Ulrich. ${ }^{(5)}$
Rebater com uma mão: a criança precisa realizar um balanço para trás com a raquete quando a bola é arremessada, além de dar passos em direção à bola com o pé não preferido. Após, ela deve bater na bola para frente enviando-a em direção à parede, além de realizar um follow through (movimento contínuo) em direção ao ombro não preferido.

Figura 8 - Habilidade rebater com uma mão.

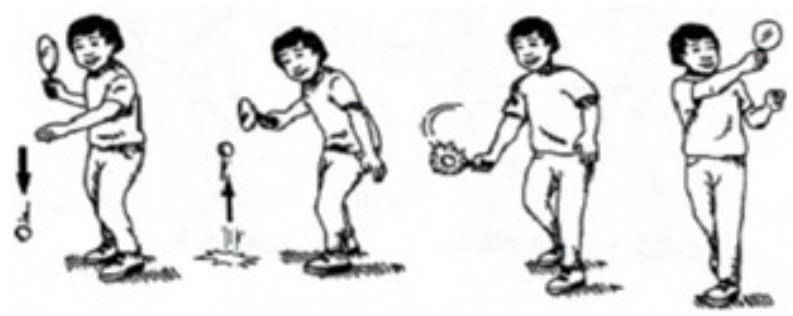

Fonte: Ulrich. ${ }^{(5)}$

Quicar: a criança deve contatar a bola com uma mão ao redor da altura da cintura, empurrar a bola com a ponta dos dedos e manter o controle da bola por quatro quiques consecutivos sem mover os pés para recuperar a bola.

Figura 9 - Habilidade quicar.
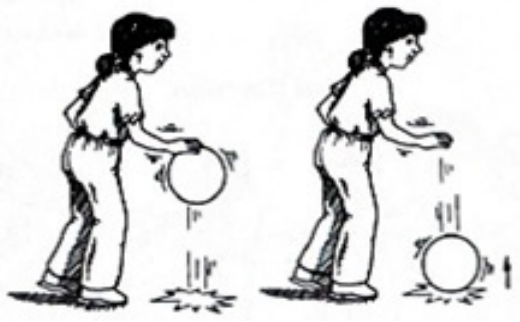

Fonte: Ulrich. ${ }^{(5)}$

Pegar: as mãos da criança são posicionadas em frente ao corpo com os ombros flexionados, e deve-se estender os braços para alcançar a bola conforme ela chega e pegá-la somente pelas mãos.

Figura 10 - Habilidade pegar.

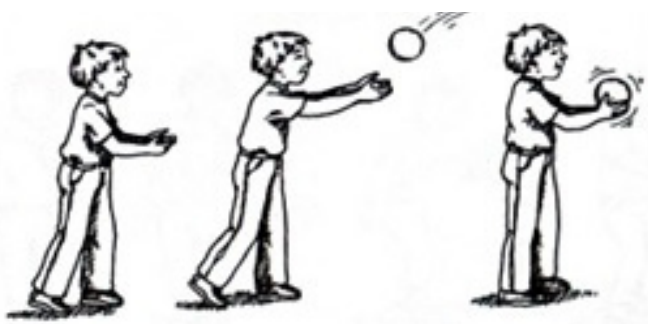

Fonte: Ulrich. ${ }^{(5)}$ 
Chutar: a criança deve realizar uma aproximação rápida e contínua em direção à bola, realizar um passo largo ou salto antes de entrar em contato com a bola; o seu pé que não está quicando se posiciona perto da bola e a realização do chute deve ocorrer com o peito do pé preferido.

Figura 11 - Habilidade chutar.

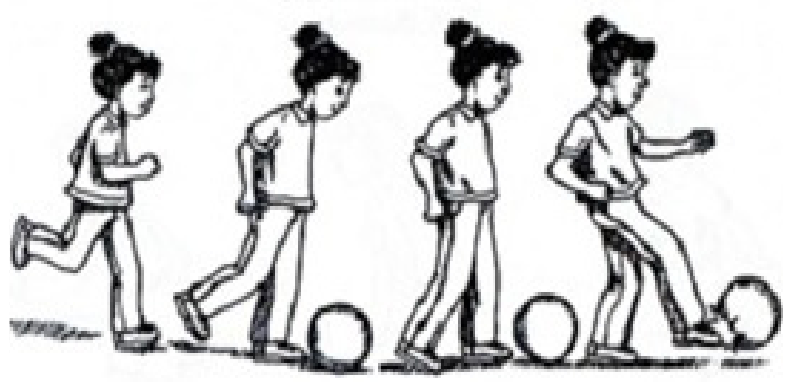

Fonte: Ulrich. ${ }^{(5)}$

Arremesso por cima: a preparação é iniciada com um movimento para baixo da mão e do braço. É realizada rotação do quadril e dos ombros para um ponto em que o lado de não arremesso volta-se para a parede, além de realizar passos com o pé em oposição à mão que está em direção à parede. A mão que está jogando segue o follow through ao longo do corpo após a liberação da bola em direção ao quadril do lado que não está jogando.

Figura 12 - Habilidade arremesso por cima.

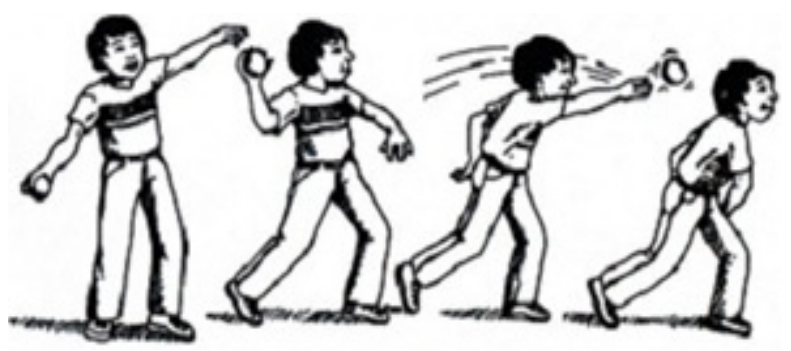

Fonte: Ulrich. ${ }^{(5)}$

Lançamento por baixo: a mão preferida balança para baixo e para trás alcançando atrás do tronco, são realizados passos para frente com o pé em oposição à mão de lançamento, a bola é lançada para frente batendo na parede sem quicar e a mão faz o follow through depois que a bola alcança o nível do peito.
Figura 13 - Habilidade lançamento por baixo.
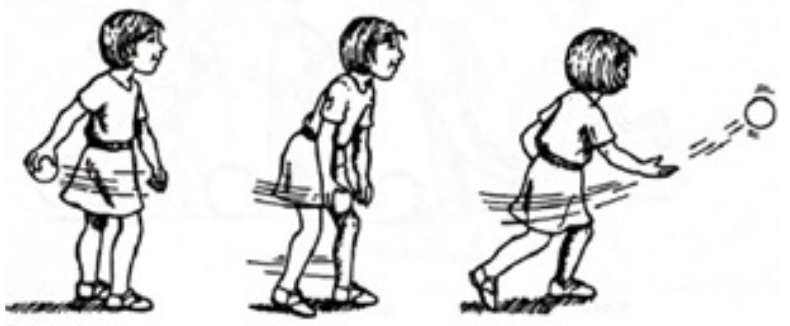

Fonte: Ulrich. ${ }^{(5)}$

\section{Intervenção}

Essa intervenção foi implementada através do projeto de extensão "Infância e movimento: diversificando vivências motoras", que ocorria no CEI-UEL. Este projeto, que se desenvolveu de 2017 a 2020, incluía uma intervenção realizada uma vez por semana, com duração de uma hora cada sessão, em que eram trabalhadas habilidades de estabilização, manipulação e locomoção. Para a aplicação das habilidades motoras com as crianças, as mesmas eram incluídas em jogos e brincadeiras a fim de que conforme as crianças praticassem as atividades de maneira lúdica e motivante, pudessem ao mesmo tempo ser estimuladas motoramente, mas também sentir interesse para participar e continuar participando das atividades propostas. Jogos como estafetas, queimada, pega-pega, dentre outros, foram adaptados para as condições motoras das crianças a fim de que pudessem participar das atividades, respeitando suas possibilidades e limitações. Essas atividades eram planejadas e ministradas por uma docente, professora de Educação Física, e estudantes do curso de bacharelado em Educação Física da UEL.

A intervenção foi composta por 29 sessões, ao longo de oito meses (similar à de estudos prévios, ${ }^{(6-7)}$ ) divididas de acordo com as habilidades a serem trabalhadas naquela sessão, ou seja, cada sessão possuía uma habilidade específica a ser trabalhada. Após quatro ou cinco sessões eram feitas uma recapitulação de tudo que havia sido feito nas sessões anteriores e a aplicação de atividades que não haviam sido realizadas por conta da disponibilidade de tempo, espaço inadequado por questões 
de chuva, outros objetos que ocupavam o local ou falta de motivação ou envolvimento das crianças para determinadas atividades propostas.

Durante a realização das atividades, os estudantes se dividiam em três grupos (as crianças com 6 anos de idade também participaram das intervenções, mas por questões relacionadas à limitação de coleta e análise de dados foram aplicados outros testes para esse grupo etário), sendo que de dois a três estudantes ministravam as atividades (previamente discutidas e planejadas) para cada grupo de crianças, em três espaços diferentes da CEI, com as mesmas atividades, mas com pequenas adaptações, de acordo com características específicas da idade do grupo. A professora coordenadora do projeto acompanhava os grupos e as atividades, assim como as professoras regentes e estagiárias da própria $\mathrm{CEI}$.

\section{Procedimentos}

As coletas de dados foram realizadas em dois períodos, sendo estes: pré-intervenção e pósintervenção, com intervalo de oito meses entre os dois testes (período de intervenção).

As coletas foram realizadas da seguinte maneira: as crianças foram separadas em duplas e levadas até o local de filmagem e gravação do teste; nesse local havia dois pesquisadores, um responsável por fazer a gravação das duas tentativas válidas de cada habilidade que as crianças iriam realizar e o outro responsável por explicar e mostrar a execução da habilidade para a criança. Para cada duas habilidades do subteste (locomoção ou habilidades com bola, de acordo com as habilidades descritas previamente no subcapítulo 2.2 - Teste), dois pesquisadores aguardavam a chegada das crianças, que após realizarem essas habilidades se dirigiam a outro local (conduzidas por um pesquisador) para realizar outras duas habilidades, e assim por diante. Ao chegarem ao local da filmagem, as crianças recebiam demonstrações da habilidade que iria ser gravada, sendo oferecida para as crianças uma tentativa de familiarização da habilidade e duas tentativas válidas para o teste, sendo essas duas tentativas gravadas para posterior análise.
Para a realização das habilidades motoras do TGMD-3, como devem ser orientadas e realizadas de acordo com critérios próprios e específicos do teste, não foram realizadas em contextos de jogos ou brincadeiras, e sim foram realizadas de maneira individual (cada tarefa motora era filmada individualmente a fim de que pudessem ser apresentados na realização da mesma todos os componentes de movimento envolvidos na habilidade). Ou seja, para a realização da atividade de chutar, por exemplo, o pesquisador demonstrava o movimento do chute para a criança e após essa demonstração a criança realizava o chute com uma bola, sozinha, direcionando a bola para frente, sem qualquer contexto de jogo ou brincadeira envolvido nessa ação. Esse rigor foi necessário para que os movimentos filmados pudessem ser analisados posteriormente, de acordo com os critérios do teste. Depois de gravadas as habilidades, as crianças retornavam para a sala de aula e mais duas crianças eram chamadas para a realização da coleta. As coletas de dados, como envolviam diferentes habilidades e muitas crianças, não foram realizadas no mesmo dia, em média eram gravadas quatro habilidades por dia.

\section{Variáveis avaliadas}

As variáveis avaliadas neste estudo foram a somatória (soma dos pontos obtidos nos subtestes de habilidades com bola e locomoção que fornecem o valor bruto total de cada criança avaliada), o escore (relação entre o escore bruto total obtido e a idade de cada criança por meio de tabela normativa Ulrich $^{(5)}$ ) e percentil (indicação do posicionamento da criança referente à comparação de seu desenvolvimento motor aos dados normativos - Ulrich ${ }^{(5)}$ ).

\section{Análise de dados}

A tabulação dos dados foi realizada através das médias dos escores, do percentil e da somatória alcançada nos critérios do subteste de tarefas locomotoras e de habilidades com bola no pré-teste e no pós-teste. A análise de normalidade foi feita pelo teste Shapiro-Wilk. Com relação às variáveis 
de somatória e escore, os pressupostos para análise paramétrica foram alcançados; por conseguinte, foi utilizado o teste " $t$ " para medidas repetidas a fim de comparar o desempenho dos participantes entre o pré-teste e o pós-teste. Para o percentil foi empregado o teste Wilcoxon, tendo em vista que os pressupostos para análises paramétricas não foram alcançados. A análise estatística foi realizada por meio do programa estatístico SPSS ${ }^{\circledR}$ versão 20.0, adotando um nível de significância de $\mathrm{p}<0,05$.

$\mathrm{O}$ tamanho do efeito (ES) adotado para o teste " $\mathrm{t}$ " com medidas repetidas foi o " $\mathrm{d}$ " de Cohen e para o teste de Wilcoxon foi o " $r$ " $\left(r=\mathrm{d} / \sqrt{ } d^{2}+a\right){ }^{(8)}$ Rosenthal ${ }^{(9)}$ propôs esse teste como alternativa quando os critérios para empregar o "d" de Cohen não forem atendidos. O tamanho do efeito será interpretado em três magnitudes: pequeno $(0,1 \mathrm{a}$ $0,3)$, moderado $(0,3$ a 0,5$)$ e grande efeito $(>0,5) .{ }^{(10)}$

\section{Resultados}

Apresentamos na sequência os valores obtidos para as variáveis somatória, escore e percentil das crianças avaliadas neste estudo.

Sobre a somatória, podemos observar através do Gráfico 1 que para as habilidades com bola as crianças avaliadas apresentaram desempenho superior no pós-teste (média $=25,06$ ) em comparação ao pré-teste (média $=22,41$ ), mas sem diferença significativa entre os dois testes $(\mathrm{t}(16)=-1,542, \mathrm{p}=0,143$, $\mathrm{d}=0,421)$.

Para as habilidades locomotoras, a somatória das crianças avaliadas apresentou valor de desempenho superior no pós-teste (média $=30,76)$ quando comparado ao pré-teste (média $=25,82$ ), com diferença expressiva entre os dois testes $(\mathrm{t}(16)=-3,128$, $\mathrm{p}=0,006, \mathrm{~d}=0,741)$.

Gráfico 1 - Valores de somatória referentes aos pré-testes e aos pós-testes de habilidades com bola e locomoção.

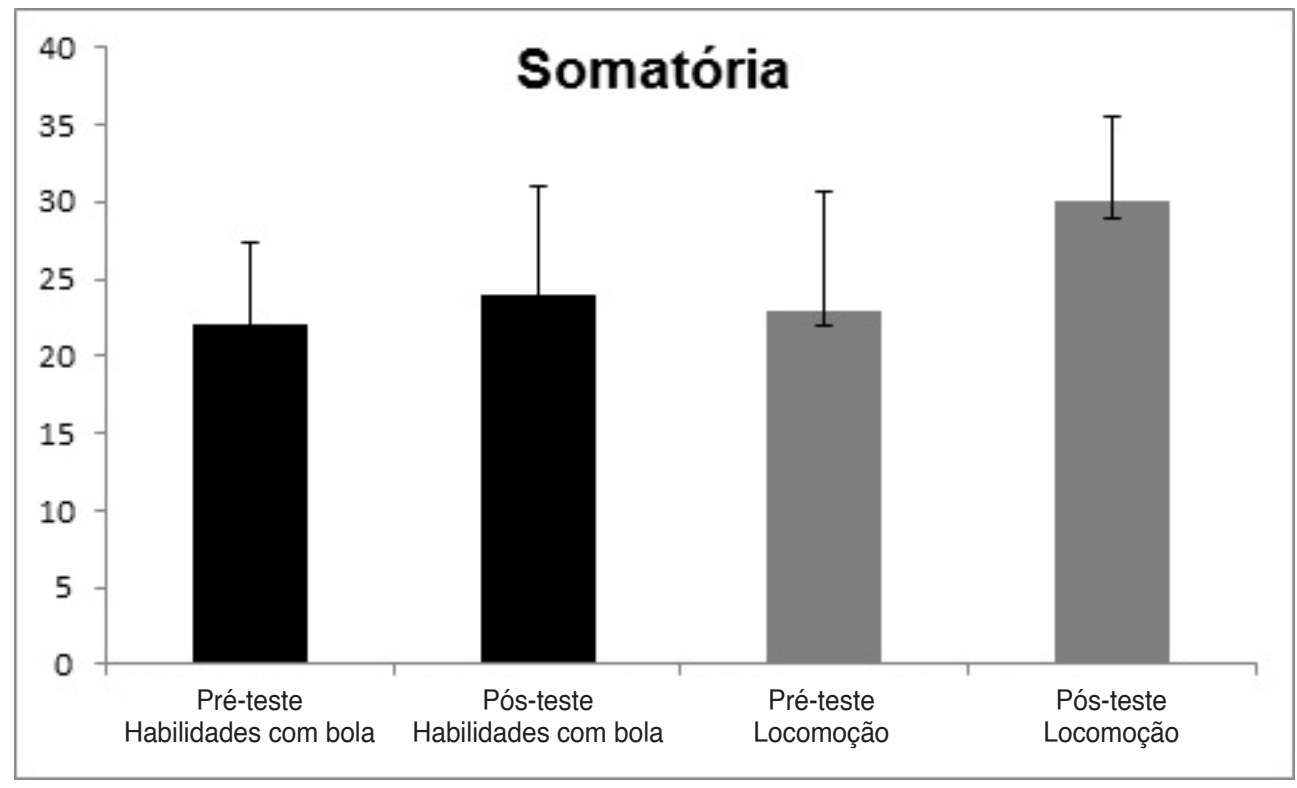

Fonte: as autoras.

Quanto ao percentil, percebemos no Gráfico 2 que para o subteste de habilidades com bola as crianças apresentaram desempenho inferior no pósteste (média $=56,18)$ quando comparado ao pré-teste (média $=59,18$ ), porém sem diferença significativa entre os dois testes $(Z=-0,487, p=0,626, r=-0,162)$.
E para o subteste de locomoção, o percentil das crianças avaliadas apresentou maior valor no desempenho no pós-teste (média=78,24) em comparação ao pré-teste (média $=71,06)$, sem diferença significativa entre os dois testes $(Z=-1,35, p=0,177$, $\mathrm{r}=0,403)$. 
Gráfico 2 - Valores de percentil referentes aos pré-testes e aos pós-testes de habilidades com bola e locomoção.

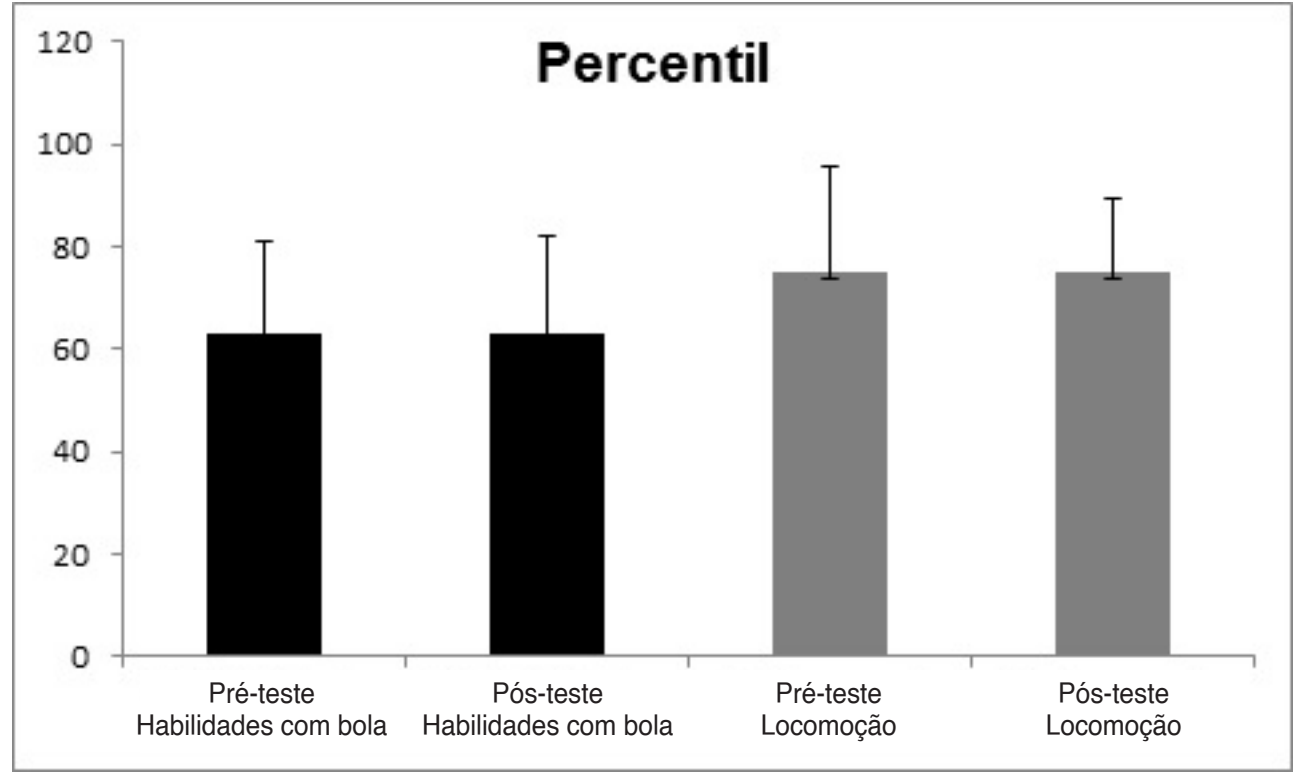

Fonte: as autoras.

Sobre o escore, podemos notar por meio do Gráfico 3 que as crianças apresentaram desempenho inferior no pós-teste de habilidades com bola (média $=10,53)$ em comparação ao pré-teste (média $=10,82)$, porém sem diferença significativa entre os dois testes $(\mathrm{t}(16)=0,496, \mathrm{p}=0,626, \mathrm{~d}=-0,187)$.
Com relação ao subteste de locomoção, as crianças avaliadas apresentaram desempenho superior para o escore no pós-teste (média $=12,71$ ) quando comparado ao pré-teste (média $=12$ ), mas não houve diferença significativa entre os dois testes $(t(16)=-1,289, p=0,216, d=0,352)$.

Gráfico 3 - Valores dos escores obtidos nos pré-testes e nos pós-testes de habilidades com bola e locomoção.

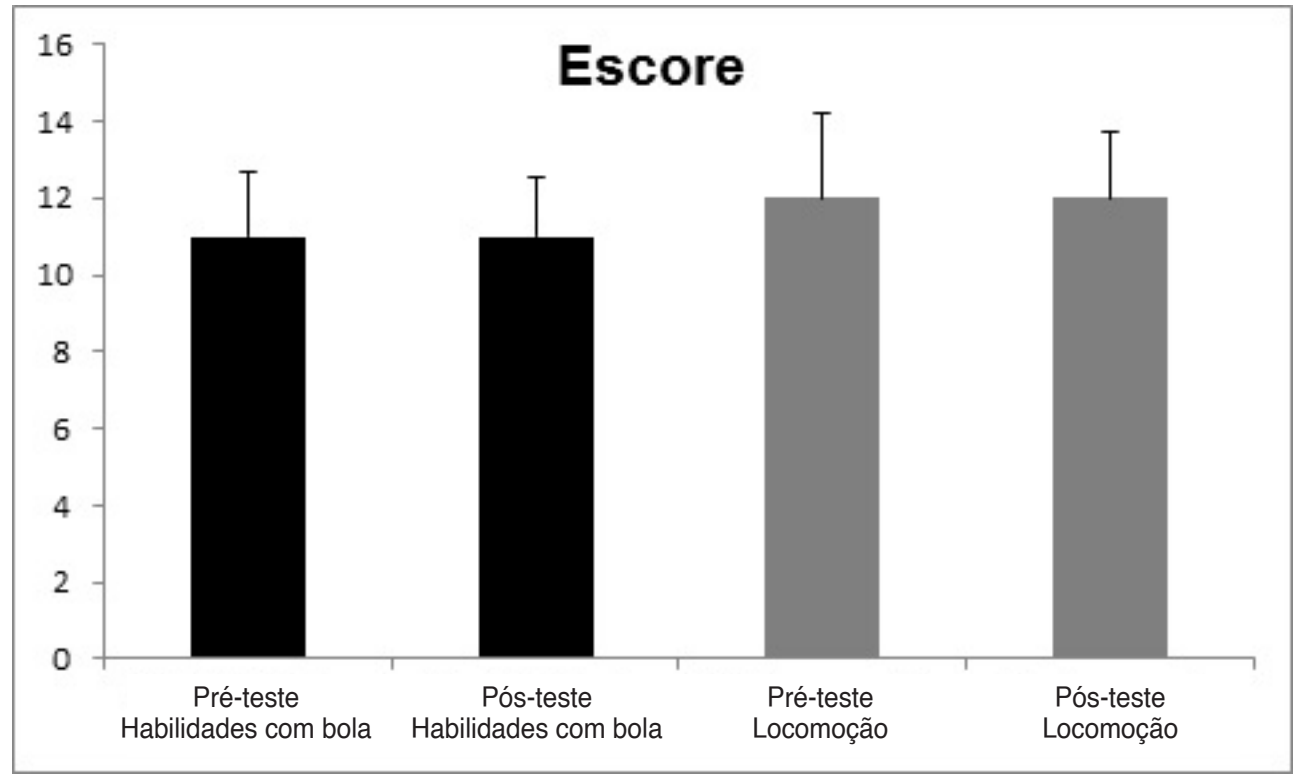

Fonte: as autoras. 


\section{Discussão}

O objetivo do presente estudo foi avaliar o desempenho motor de crianças com idade entre 4 e 5 anos, por meio do TGMD-3, antes e após uma intervenção motora, realizada no CEI, campus da Universidade Estadual de Londrina.

Os resultados de nosso estudo mostraram, de forma geral, que a somatória (tanto para o subteste com bola, como no de locomoção), o percentil (somente para o subteste de locomoção) e o escore (também somente para o subteste de locomoção) no pós-teste foram superiores quando comparados ao pré-teste, demonstrando que a intervenção aplicada em nosso estudo pode ter contribuído para a melhora no desempenho de habilidades motoras fundamentais das crianças avaliadas, com tendência de melhora maior para o subteste de locomoção.

Resultado semelhante foi encontrado por Bardid $^{(6)}$ em estudo que também verificou o efeito de uma intervenção motora, avaliando crianças (3 a 8 anos de idade) e com menor tempo de prática (cada sessão durava de 15 a 30 minutos); além do grupo de intervenção, Bardid ${ }^{(6)}$ também avaliou um grupo controle. Outro diferencial deste estudo com o nosso é que a versão anterior do TGMD, o TGMD-2 foi aplicado. No entanto, diferente de nossos resultados, no estudo de Bardid ${ }^{(6)}$ os resultados demonstraram que as crianças do grupo intervenção obtiveram melhores resultados nas habilidades locomotoras e também nas habilidades com bola em comparação ao grupo controle (houve diferença significativa entre os grupos), demonstrando a eficácia da intervenção para melhora das habilidades motoras fundamentais, principalmente as locomotoras.

De maneira similar ao tempo de intervenção utilizado em nosso estudo, Johnson e colaboradores $^{(7)}$ investigaram crianças de 3 a 5 anos e o efeito de um intervenção motora de nove meses, mas nesse estudo com frequência semanal de duas vezes e aplicando um clima de motivação à intervenção. Ressalta-se que nesse estudo a versão 3 do TGMD foi aplicada, o que se assemelha também ao nosso estudo. Mas de maneira diferente do nosso estudo, os resultados ${ }^{(7)}$ demonstraram melhora significativa de desempenho para os dados brutos do teste (que em nosso estudo denominamos de somatória) tanto para as habilidades locomotoras como de controle de objetos entre o pré-teste e o pós-teste.

Em estudo realizado por Silva Souza, ${ }^{(11)}$ os resultados, obtidos através do TGMD-2, mostraram melhoras significativas para a variável score tanto para as habilidades de locomoção como também para as habilidades com bola no grupo que realizou intervenção. Em nosso estudo esses resultados foram encontrados, mas somente para as habilidades de locomoção, através da variável somatória, uma vez que com relação ao escore não foram apresentadas diferenças significativas para as habilidades de locomoção e as habilidades com bola. Vale destacar que o estudo realizado por Silva Souza ${ }^{(11)}$ analisou crianças com idades entre 7 e 10 anos e que realizavam aulas de Educação Física escolar além do programa de intervenção aplicado pelos autores, ao contrário do presente estudo, que foi realizado com crianças entre 4 e 5 anos e que não possuíam aulas de Educação Física escolar, portanto a única atividade realizada foi a do programa de intervenção.

Já no estudo de Palmer, Chinn e Robinson, ${ }^{(12)}$ os resultados do score apresentaram uma mudança mais elevada, quando relacionados às pontuações brutas das habilidades de locomoção e habilidades com bola para o grupo que realizou a intervenção, quando comparado ao grupo controle entre o pré-teste e o pós-teste, com diferença significativa nessas comparações. Nesse estudo as crianças (média de idade de 4,4 anos) realizavam entre 40 e 45 minutos de atividades todos os dias da semana, sendo que três vezes na semana as atividades eram de intervenção e duas vezes na semana as atividades eram de jogos ao ar livre; para o grupo controle eram realizadas apenas as atividades ao ar livre durante os cinco dias da semana. Resultados semelhantes, demonstrando efeito positivo de intervenção motora, também foram encontrados no estudo de Palmer, Chinn, Scott-Andrews e Robinson. ${ }^{(13)}$ 
Importante ressaltar que usamos a versão recente do TGMD em nosso estudo (TGMD-3), e alguns resultados que trazemos aqui utilizaram a versão 2 do teste (TGMD-2). Ainda que as versões dos testes sejam diferentes, acrescentamos aqui resultados que demonstraram ${ }^{(13)}$ grande concordância dos dois testes (TGMD-2 e TGMD-3) para a variável somatória e uma concordância um pouco menor, mas aceitável, da variável percentil. Nesse sentido, esses dados nos fornecem subsídios para compararmos nossos resultados obtidos através do TGMD-3 com estudos prévios, utilizando a versão 2 do teste.

Com duração um pouco menor na intervenção (24 sessões) que em nosso estudo, achados prévios $^{(14-15)}$ demonstraram efeitos positivos (com melhora significativa de desempenho após a intervenção) tanto para a variável escore ${ }^{(14)}$ como para a variável percentil,(15) enfatizando a importância da prática motora para a melhora de desempenho no TGMD (subtestes de habilidades com bola e de habilidades de locomoção).

Os efeitos positivos de intervenções motoras também foram encontrados na aplicação do teste para crianças mais velhas (em comparação à faixa etária investigada em nosso estudo), ou seja, para crianças de 6 a 10 anos. ${ }^{(15-17)}$

Dentre os estudos realizados usando intervenções e avaliação do desempenho pelo TGMD, observamos que alguns parâmetros se diferenciam nas intervenções, como variação do período da intervenção, com tempo mínimo de intervenção de oito semanas ${ }^{(18)}$ a oito meses; ${ }^{(19)}$ com variação de número de sessões, com mínimo de 12 sessões $^{(16)}$ a 36 sessões, ${ }^{(20)}$ com variação de frequência semanal de uma vez por semana ${ }^{(6)}$ a cinco vezes por semana $^{(12)}$; e com duração de 15 minutos $^{(16-17)}$ a 60 minutos $^{(15)}$ a sessão.

Nesse sentido, no que se refere à duração total da intervenção, frequência e duração da sessão, como podemos observar no que foi descrito previamente, há uma grande variação no formato de intervenções motoras, com o intuito de aprimorar o desempenho motor de crianças. A partir dessa perspectiva nosso estudo encontra-se dentro dos parâmetros previamente aplicados em intervenções prévias.

Enquanto no presente estudo o desempenho nas habilidades com bola (variáveis percentil e escore) foi inferior (maior no pré-teste e menor no pós-teste), no estudo de Altunsöz e Goodway ${ }^{(18)}$ os resultados foram diferentes. Na intervenção ${ }^{(18)}$ com crianças de 3 a 5 anos, de oito semanas, houve priorização de uso de habilidades com bola e instrução cinestésica, além de envolvimento dos pais com estimulação motora. Outra diferença com nosso estudo foi a versão utilizada do teste, o TGMD2. Os resultados indicaram que houve melhora do desempenho nas habilidades com bola (percentil) do pré-teste para o pós-teste entre as crianças que fizeram parte da intervenção, e aquelas que não fizeram não alcançaram melhorias significativas, mesmo realizando atividades de caráter lúdico ao ar livre e jogos, demonstrando a importância da intervenção motora para o desempenho de habilidades com bola para as crianças avaliadas.

Já em relação aos conteúdos motores aplicados nas intervenções de estudos prévios, é relevante destacar que as crianças que participaram de nosso estudo também participavam de atividades ao ar livre (parquinho, amarelinha ou campinho de futebol), com atividades livres e monitoradas por professoras da sala; no entanto, em nosso estudo a frequência e controle de realização dessas atividades não foi controlada.

Também com o objetivo de verificar os efeitos de um programa de intervenção, Lobo ${ }^{(21)}$ realizou um estudo com a utilização de dois grupos, sendo um grupo de intervenção e um grupo controle. No seu estudo, as crianças do grupo controle possuíam 50 minutos diários para brincar livremente pelo parque da escola e as crianças do grupo que participou da intervenção realizavam três dias na semana a mesma atividade (livres pelo parque da escola) e nos outros dois dias realizavam aulas de Educação Física com 50 minutos de duração, durante três meses. Após a intervenção, Lobo ${ }^{(21)}$ encontrou aumento significativo nos valores dos 
escores brutos locomotor e de habilidades com bola do grupo que realizou a intervenção, enquanto que o grupo controle não apresentou grandes mudanças; importante ressaltar que antes da intervenção os dois grupos possuíam valores parecidos, tanto no escore bruto locomotor como no de habilidades com bola.

Em outro estudo, ${ }^{(20)}$ envolvendo 40 meninas com idade entre 7 e 10 anos, foram avaliadas as habilidades básicas do basquete através do teste TGMD-2. Para a realização do estudo ${ }^{(20)}$ as meninas foram divididas em dois grupos, sendo um experimental e um controle. O grupo experimental recebeu um treinamento com exercícios do minibasquete durante 12 semanas em um total de 36 sessões, enquanto o grupo controle não recebeu nenhum treinamento interventivo. Esse estudo obteve como resultado um progresso nas pontuações do quociente de movimento, tanto para o grupo controle como para o grupo experimental no pósteste em relação ao pré-teste, com destaque para o grupo experimental, cuja melhora de desempenho foi significativamente superior em comparação às pontuações do grupo controle no pós-teste.

\section{Conclusão}

De maneira geral, podemos concluir a partir dos resultados encontrados em nosso estudo que a intervenção aplicada no estudo foi positiva para o desempenho das habilidades motoras fundamentais em crianças de 4 e 5 anos, e mais ainda para as habilidades locomotoras. Ainda, inferimos que poderíamos obter melhores resultados caso as atividades de intervenção acontecessem com maior frequência ao longo da semana, já que as atividades motoras propostas em nossa intervenção eram realizadas uma vez por semana e podem não ter sido suficientes para modificar de forma mais robusta o desempenho motor das crianças; acreditamos que a realização de atividades motoras duas vezes ou mais na semana pode ser mais efetiva para melhorar o desempenho motor das crianças. Vale destacar uma outra limitação em nosso estudo que foi o não controle das atividades que as crianças realizavam na própria instituição (atividades motoras livres, como brincar de pega-pega, andar de motoca, jogar futebol ou outros jogos envolvendo movimentos corporais) e também em horários fora da instituição (como prática no contraturno de modalidades esportivas como futebol, ballet, natação, lutas, ou outras atividades comumente oferecidas para crianças nessa faixa etária) e que podem ter influenciado nos resultados encontrados.

Recomendamos para estudos posteriores que venham a investigar intervenções motoras com crianças, como sugestão, que utilizem grupo controle e verifiquem possíveis diferenças entre frequência semanal e duração do programa, a fim de que essas variáveis possam ser melhor compreendidas e possam auxiliar na elaboração e implementação de futuras intervenções motoras com crianças.

\section{Referências}

1 Gorla JI. Coordenação motora de portadores de deficiência mental: avaliação e intervenção. [dissertação]. Campinas: Universidade Estadual de Campinas; 2001.

2 Dias IMG. Análise do teste TGMD-2 em crianças com deficiência mental. [trabalho de conclusão de curso]. Campinas: Universidade Estadual de Campinas; 2008.

3 Gorla JI. Desenvolvimento de equações generalizadas para estimativa da coordenação motora em crianças e adolescentes portadores de deficiência mental. [tese]. Campinas: Unicamp; 2004.

4 Valentini NC, Barbosa MLL, Cini GV, Pick RK, Spessato BC, Balbinotti MAA. Teste de desenvolvimento motor grosso: validade e consistência interna para uma população Gaúcha. Rev Bras Cineantropometria e Desempenho Hum. 2008;10(4):399-404.

5 Ulrich DA. TGMD-3: test of gross motor development. $3^{\text {rd }}$ ed. Austin, Texas: Proed; 2019.

6 Bardid F, Lenoir M, Huyben F, De Martelaer K, Seghers J, Goodway JD, et al. The effectiveness 
of a community-based fundamental motor skill intervention in children aged 3-8 years: Results of the "Multimove for Kids" project. J Sci Med Sport. 2017;20(2):184-9.

7 Johnson JL, Rudisill ME, Hastie P, Wadsworth $\mathrm{D}$, Strunk K, Venezia A, et al. Changes in fundamental motor-skill performance following a nine-month mastery motivational climate intervention. Res Q Exerc Sport. 2019 Dec; 90(4):517-526. doi: 10.1080/02701367.2019. 1628909 .

8 Cooper H, Hedges LV, Valentine JC. Handbook of research synthesis and meta-analysis. $2^{\text {nd }}$ ed. New York; 2009.

9 Rosenthal R. Parametric measures of effect size. In: Cooper H, Hedges LV, Valentine JC, editors. The handbook of research synthesis and meta-analysis. $2^{\text {nd }}$ ed. New York: Russell Sage Foundation; 1994. p. 231-44.

10 Cohen J. Statistical power analysis for the behavioral sciences. $2^{\text {nd }}$ ed. New York: Academic Press; 1988.

11 Silva Sousa FC, Bandeira PFR, Valentini NC, Silva Ramalho MH, Carvalhal MIM. Impacto de um programa social esportivo nas habilidades motoras de crianças de 7 a 10 anos de idade. Motricidade. 2016;12(1):69-75.

12 Palmer KK, Chinn KM, Robinson LE. The effect of the CHAMP intervention on fundamental motor skills and outdoor physical activity in preschoolers. J Sport Heal Sci. 2019;8:98-105.

13 Palmer KK, Chinn KM, Scott-Andrews KQ, Robinson LE. An intervention-related comparison of preschooler's scores on the TGMD2 and TGMD-3. Perceptual and Motor Skills. 2021;128(4): 1354-1372.

14 Lee J, Zhang T, Chu TL, Gu X. Effects of a need-supportive motor skill intervention on children's motor skill competence and physical activity. Children. 2020;7(3):21.

15 Valentini NC. A influência de uma intervenção motora no desempenho motor e na percepção de competência de crianças com atrasos motores. Revista Paulista de Educação Física. 2002; 16(1):61-75.
16 Braga RK, Krebs RJ, Valentini NC, Tkac CM. A influência de um programa de intervenção motora no desempenho das habilidades locomotoras de crianças com idade entre 6 e 7 anos. Rev da Educ Física/UEM. 2009;20(2):171-81.

17 Van Keulen GE, Benda RN, Ugrinowitsch H, Velentini NC, Krebs RJ. Influence of an intervention using practices random and blocked in the performance of object control skills. J Phys Educ. 2016;27(1):1-11.

18 Altunsöz IH, Goodway JD. Skiping to motor competence: the influence of project successful kinesthetic instruction for preschoolers on motor competence of disadvantaged preschoolers. Physical Education and Sport Pedagogy. 2016; 21(4):366-85.

19 Rodrigues D, Avigo EL, Leite MMV, Bussolin RA, Barela JA. Desenvolvimento motor e crescimento somático de crianças com diferentes contextos no ensino infantil. Motriz. 2013;19 (3):49-56.

20 Fotrousi F, Bagherly J, Ghasemi A. The compensatory impact of mini-basketball skills on the progress of fundamental movements in children. Procedia - Soc Behav Sci. [Internet]. 2012 [cited 2021 Nov 12]; 46:5206-10. Available from: https://linkinghub.elsevier.com/retrieve/ pii/S1877042812021465

21 Lobo LM. Educação física na educação infantil: influência de uma unidade de ensino de um programa de educação física no desenvolvimento motor dos alunos de uma escola de Educação Infantil do município de São Paulo. [tese]. São Paulo: Universidade de São Paulo; 2017.
Recebido em: 23 mar. 2021

Aceito em: 3 dez. 2021 
Duarte, M. E. O.; Rogeri, L. A.; Dascal, J. B. 